\title{
USING THE BIG PICTURE APPROACH TO INTEGRATE SUSTAINABILITY IN BUSINESS-TO-BUSINESS MARKETING
}

\author{
Tracy L. Gonzalez-Padron, University of Colorado Colorado Springs, USA \\ Jeffery Ferguson, University of Colorado Colorado Springs, USA \\ John Milliman, University of Colorado Colorado Springs, USA
}

\begin{abstract}
Sustainability (or being "green") has been identified as a key macro megatrend (Lubin and Esty 2010), but many organizations are struggling with how to operationalize the concept of sustainability for a competitive advantage (Nidumolu, Prahalad and Rangaswami 2009). This is particularly important for sustainability business-to-business marketing where there are numerous opportunities for creating a competitive advantage (Sharma, Iyer, Mehrotra, \& Krishnan, 2009). The Big Picture marketing framework (Nordhielm 2006) offers one potential way for organizations to address this issue because it provides a framework that promotes a structured, disciplined approach to market analysis and decision-making. This research examines how Ecolab Inc. uses The Big Picture framework to include sustainability variables into its business-to business marketing and new product development processes.
\end{abstract}

Our research focuses on two key aspects of The Big Picture. The first is identification of core competencies that is part of the organization's "business objective," including those related to sustainability. The Big Picture attempts to orient an organization to select potential opportunities related to trends in the macro environment that align with its core competencies. Sustainable products represent an opportunity for firms who have a degree of competence in sustainability or are willing to invest in developing expertise in this area (Chen 2008). A second important aspect of The Big Picture is the emphasis placed on developing and exploiting dynamic variables. A dynamic variable is a new variable (such as sustainability) on which the firm seeks to outperform other competitors in the category.

This interview based case study focuses on how The Big Picture framework can effectively integrate sustainability as a dynamic variable into the marketing and new product development processes at Ecolab Inc. The principal method of data collection was semi-structured interviews that began with a brief description of the study and continued with a series of questions about sustainability processes developed from the literature and reviewed by marketing and management experts. The case study of one company's path to innovative and sustainable products creates opportunities for managerial practice and further research in business-to-business sustainability marketing. Our research suggests that organizations adopting the Big Picture framework may become more competitive through focused marketing efforts to align strategy with environmental and social competencies, define clear business and marketing objectives, and accurate forecasting to determine salient dynamic sustainability variables.

References available upon request 